\title{
Exploration on Culture Landscape Design of University Campus 20
}

\author{
Zhi-Zhong Su${ }^{1, a}$ Jia-ning $\mathrm{Li}^{2, \mathrm{~b}}$ Jing-Zhong $\mathrm{Li}^{3, \mathrm{c}}$ \\ 1 Huaiyin Institute of Technology, Huai'an Jiangsu 223003, China \\ 2 Central South University School of Resources and Safety Engineering \\ 3Jiangsu Polytechnic of Finance and Econcmics \\ szz581224@163.com,
}

\begin{abstract}
Keywords: University Campus; Culture; Landscape; design
\end{abstract}
Abstracts: University campus landscape as a unique cultural space should embody the humanistic value and cultural connotation undoubtedly. In the article, by investigating ten universities in Jiangsu Province and by analyzing the current campus culture and landscape construction, the author set forth the necessity of campus landscape planning and cultural construction, expounds the basic principles of modern campus landscape construction, proposes and designs the campus scene, the section of the culture and the landscape construction. The purpose of the article is to enhance the university campus cultural landscape level further, to deepen the cultural atmosphere and the cultural connotation, to show the humanistic spirit of university campus culture.

functional aspects which lead students to trample green and administrator not to prevent. Furtherm1

\section{Preface}

It points out the culture is the blood of the nation and the spirit of people in the Eighteenth National Congress of the CPC. We must promote the socialist cultural development and prosperity, improve the national cultural soft power, play the role of cultural leading fashion, educating people, serving society and promoting development to build a well-off society comprehensively and to realize the great rejuvenation of the Chinese nation.

In recent years, the establishment of the basic strategy of prospering the nation through science and education has greatly promoted the development of education. University as a higher education which breeds technology and sets knowledge innovation, knowledge production, knowledge dissemination and knowledge application as a whole, has been from the edge of society to the center of the community. Higher education has never been concerned by the government and the whole society as it is today. The number of colleges and universities in China has increased dramatically. The environment of university campus as a side of material civilization must reflect the spirit of the campus, school ethos and cultural connotation on a deeper level and create a good learning, working and living environment in order to develop the future of high-tech talents. We paid more attention to preach the doubts in the classroom, to construct the campus' hardware such as a large number of the fundamental construction of the campus, teaching function, facilities and green investment and so on and neglected the construction of environmental culture in university campus. Many students say our campus like a park proudly. Do they know the campus is different from the park? The cultural construction of the university campus has been more and more attention by the society with the development of the development of education and the promotion of the social connotation of education.

The beautiful university campus occupies large area which has more complete campus facilities and has more lakes, green, flowers, sculpture, etc now. In the course of the study of ten universities, 
there are some problems which need to be further improved in landscape function and aesthetics. Firstly, the construction of university campus can meet the practical function of running a school, but lack cultural atmosphere. The class and dining and leisure walk and Lake Road cannot meet the requirements of campus culture's propaganda. Defects also exist in planning and ore, campus lake road lack safety facilities as guardrail at present, which causes a hidden trouble and accident to the students' personal safety.

\section{Necessity of the university campus' culture landscape design}

Campus planning should fully reflect and express the concept of education, and provide the material platform for the implementation of the concept of Education. Great changes have taken place in education with the rapid development of science and technology and the shown signs of knowledge economy. We not only put forward higher requirements to the cultural construction of university campus but also bring new ideas for the campus landscape planning with the transformation of education idea. We not only attach importance to modern university campus environment, but also pay more attention to provide space for communication and create a campus culture atmosphere, academic atmosphere. In this article, we will focus on how to make the campus environment, cultural atmosphere, cultural landscape harmony and unity, to achieve harmony between man and nature, to meet the new requirements of college education, to create a natural, humane and open campus landscape, to provide a reference for contemporary university campus landscape planning and cultural construction.

Modern university campus is not only a place for students to learn knowledge, but also to cultivate students' quality and improve the environment of culture. Therefore, the university campus should be not only a rich nature of the ecological environment, but also can purify the mind, cultivate sentiment, influence and educate students subtly. The concept of campus landscape design is to ask that the buildings, environment such as flowers, trees, roads and galleries and people are in harmony, so that each part can influence, interact, help and enhance mutually. Contemporary college students are young people who are active thinking and full youthful spirit. University campus is the place to study and live, which main role is to provide students with a cultural atmosphere of learning, living place. The beautiful environment profound cultural atmosphere, active academic atmosphere which reflect Student First and serve them are created to meet the use function of college students. on the one hand, students in the classroom accept the baptism of knowledge and culture, on the other hand, they enhance the cultivation of sentiment in a relaxed, harmonious and beautiful campus environment. We can realize the harmonious development of teaching and educating people in Contemporary Universities by doing this.

\section{Planning principles of landscape construction}

\section{Functional principle}

Campus planning should take into consideration the functional principle of running a school which divides into direct function and indirect function. The direct function is to use. When students enrolled and the use of land achieve the modest amount, it inevitably lead to some problems such as long distance between the functions, long travelling time for students, instant traffic flow, difficulties using part of the facility. So the functional principle which is Form Follows Function is one of the important principles of the campus landscape planning and design. Indirect function refers to the influence of the campus environment on education. The campus environment is one of the important aspects of education function. University campus landscape on the role of people's 
education is not the other landscape can be compared. As Churchill said: " People shaped the environment, environment has created a person". The university is a place to cultivate talents and develop intelligent. It needs a campus environment which can reflect the function of the education. A beautiful campus environment can help to improve people's culture, to enhance self-confidence, to promote interpersonal and information exchange, to cultivate the patriotic spirit. During the university period, students are experiencing the growth period of the moral experience. The spiritual cultivation is very important to the growth of his life.

\section{Ecological and continuity principle}

With the large-scale construction of campus, the planning and design should be binding and make full use of natural conditions, protection and construction of ecological system of the campus, economic reasonable using land and other natural resources, realize to moderate demand and the optimal return balance, the creation of ecology, the garden of the campus environment. The original ecological environment should try to let it integrate naturally into the campus environment and wedge into the green campus environment. Natural landscape is extended to artificial landscape and expanded the historical context in the campus. The campus landscape environment and building monomer should be coordinated and integrated with each other, and combine to form the whole continuity. It should be fully considered in the future development so that the structure of planning flexibly adapt to future changes and meet the requirements of sustainable development.

\section{Principle of highlighting features}

School is a special space environment where we cannot simply be understood as a place to teach students knowledges, it is more like a community of people living together. The design should highlight the unique tension and deep cultural heritage of the site, abandon the monotonous landscape and show the diversity of the landscape. At the same time, the special educational function of the school also gives its different characteristics: to highlight the campus atmosphere, to emphasize the campus culture, to orient people.

In the overall atmosphere, the university should be a quiet atmosphere. Campus space should not only reflect the characteristics of subjects in texture space, but also provide with a slight change in quiet place to observe heart and with the expression character of ritual space. Designers should grasp the development trend of higher education, comply with the requirements of the times, be rich in national cultural characteristics, absorb the essence of traditional garden and Chinese traditional campus landscape design, and learn from foreign advanced campus landscape design theory. On the basis of the overall quiet atmosphere, we not only emphasize the scientific atmosphere and academic atmosphere, but also pay attention to the exchange of space and create a campus culture. In outstanding campus culture, a good university campus environment is a three-dimensional, colorful, charming, silent textbook. It not only provides students with a variety of physical and mental stimulation, but also creates a good condition for the spread of knowledge. The power of culture is not the teaching, but the influence. Campus environmental culture should reflect the theme of humanities and technology, humanities is the orientation of technology, science is the foundation of humanity.Humanistic education and science education make a person with complete thought. We should make full use of the various elements of the structure and integrate into the cultural connotation to become the place of the humanities and technological knowledge.

In people oriented, the focus is to create a variety of space for the students. Campus environment needs to have public space, semi public space, semi private space. Only space diversity can meet the needs of different levels and different interests of teachers and students at different times. In fact, there is a series of landscape space in school. By creating an appropriate landscape, it can meet the teachers and students to rant, lea, communicate, gather, exercise, and can have leisure and other 
activities in public places. The window in the appropriate place can promote advanced academic and cultural ideas. The foreign language corner can carry out language exchange between teachers and students. The beautiful campus environment or a unique architectural essay can play them to the infection or shock of human spirit. All kinds of cultural activities and academic exchanges can promote national culture and other activities actively.

\section{Principle of whole}

"Integrated design" is an important idea of modern environment design. People feel the whole in the campus. The context of the overall context can be recognized. On the whole, it is the basis of the design of campus environment landscape. This feature comes from the respect and excavation of the university campus in the climate, environment, geography, natural conditions, history, culture, art. Characteristics refer to the internal and external features of the overall landscape of university campus. It reflects and analyses campus life functions, system research of culture, history and natural conditions comprehensively. The science of modern manufacturing technology refining and creating a university campus activities closely blend of landscape features.

\section{Principle of Humanity and local culture}

To research the university campus landscape environment cannot leave the campus located in the area of cultural context. The campus environment landscape is a part of the city environment. It is important to create the landscape image of the city. The landscape of the campus environment reflects the local culture and aesthetic trend. To talk about the landscape leaving the culture and aesthetics reduces the taste and style of the landscape. Beautiful landscape and rich regional culture, local aesthetics should be organic unity and harmonious coexistence. We attach importance to the humanistic principle of environmental landscape design and it rasp the connotation of landscape features from the perspective of spiritual culture. The natural environment deducts architectural style, cultural psychology, cultural psychology, aesthetic taste, folk tradition, religious beliefs and other factors. It mainly express through specific ways and give a person with an intuitive visual experience.

There is a famous saying in the West: "Rome is not caused by one day", and the university campus is not caused by a day. Campus culture is a school culture, long-term precipitation, accumulation of spiritual environment and cultural atmosphere, it is the core and soul of the campus environment. The history of a university is more longer, its tradition is more gradually condensed into the physical and chemical of the campus. University campus plant landscape is not only reflected in the specific geographical, historical, artistic and other aspects, but also highlighted the unique cultural atmosphere. As a result, the university campus not only can have the use function as a learning, living and growing up, but also play an important role in the spirit level as the physical materials exist in the material. In addition to the construction entity, the external landscape space is the most important part of the campus life. It is the important part of the campus life and the material carrier of the campus culture. Therefore, the campus landscape should be combined with the layout of the building, to meet the needs of teachers and students learning, activities, exchanges and leisure, the formation of a strong atmosphere of knowledge, but also full of vigor and vitality of the campus environment, and fully demonstrate the unique cultural landscape of the campus landscape charm.

\section{Status quo of Culture Landscape of University Campus}

\section{lack of campus cultural atmosphere}

As the construction of university campus culture, in the author's opinion, it satisfies the running of utility functions and lacks cultural atmosphere especially the new campus after the reform and opening up. 
There are many green, Lake Road and other necessary road students in class

and dining which is relatively simple and not reflect the characteristics of university campus culture. At the same time, because the design flaws make many green was trampled, there is a safety hazard that are no fence of artificial lake. There are a large campus space and space, a good sports facilities and spacious venue, highlighting the University's material and cultural heritage. But a new campus construction is in a "edge construction, use, and improve" state. Therefore, it is impossible to capture the symbolic significance of campus landscape in the new campus which is lack of historical buildings and landmarks, a history of symbolic architectural landscape, towering old trees. Therefore it need enrich the material carrier of the school spirit continuously and enhance the new campus scenery of the heavy history feeling constantly. Because the new campus is generally located in the suburbs of the city, the campus surrounding cultural and recreational facilities are relatively short, the geographical cultural atmosphere is relatively indifferent. The lack of campus culture make the new campus teachers and students lack the influence of the human environment, lack cultural sense of belonging and

asymmetry of the old school district in the early days and a period of time.

As a university campus, it is not only to have success in hardware construction, school spirit and study style construction, but also to form their own characteristics in cultural construction. Our creative thinking is that landscape and cultural construction designs are made of green, artificial lake, Lake Road so as to promote campus culture, to show the beauty of the campus, and to create a harmonious campus, to make teachers and students live in a beautiful, civilized and harmonious, cultural environment.

\section{imperfect of security facilities}

The campus artificial lake designs openly, connecting water and green space, no fence, as shown in figure 4-1.The advantage of this design is natural, open, easy to coordinate with a narrow strip of water around the green. But it ignores a very important issue - security! The density of campus population is the highest and the safety of the trip is the most important issue. The lake design openly which left the students of the trip a security risk to a certain extent. It is prone to accident and even to endanger the safety of life especially in the case of the night, rain and slippery road.

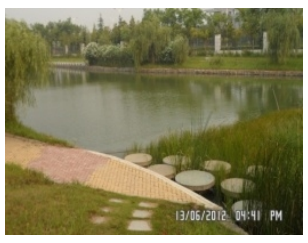

Figure 4-1 Lakeshore design openly

in a school

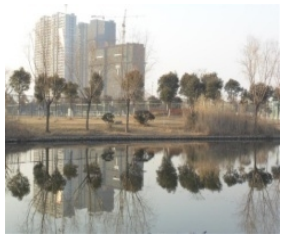

4-2 Figure the green trampled on in school

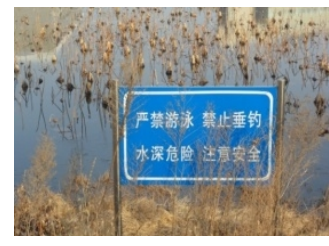

Figure 4-3 artificial lake with weeds

\section{weakness of campus landscape function}

At present, the campus landscape plays a role of decoration, and it has some purpose to beautify the campus. But as a university campus, flowers and trees should always reflect the university campus of scholarly and cultural atmosphere, the landscape has been unable to meet the demand, and strengthen the functional design is objective need.

\section{unitary of campus landscape form}

Although there are a lot of green in a new university campus, it lack its own characteristics generally. There are not much seasonal landscape and single vegetation. The landscape of a school should have variability. It will produce visual fatigue when looking for a long time especially some dining Road, Lake Road landscape that are single which can not reflect the campus culture and the 
attraction of the landscape. The students without "pause" of the thing take a shortcut and step on the lawn before and after the meal just as a passer-by, as shown in figure 4-2.There are different styles changing with the seasons by choosing the right plants. There are flowers in three quarters and green in four seasons in climatic conditions of Jiangnan District.

\section{Campus environment lack of integrated planning and management}

There are a lot of vegetation which are small trees, single species, not represented vegetation in the campus. In the overall planning, it can be clearly seen that the overall feeling is more boring without a careful design and planning. The vegetation is lack of management. The trail stepped out by the students and the artificial lake, which are serious impact on the campus as shown in figure 4-3.

To sum up, it is important and necessary to design the lake road landscape of campus. It can not only play the role of security but also achieve a certain unity and coordination with the campus environment, to make our campus historical, cultural and life characteristic.

\section{method of Lake Road Campus landscape design}

\section{Fence design}

\section{Low fence}

Used for the lake shore, set watch and safety

\section{Style 1: Ancient Chinese rhyme(as shown in figure 5-1)}

\section{Design concept:}

The fence made of steel plate is pattern frame similar with the totem of "snake" in Han Dynasty on both sides. White marble is in the middle. A rose in full bloom is at the top. Famous people are engraved in red font at the bottom. Frame and slab connect with bolt.

\section{Characteristic:}

(1) Variable form, adapt to a wide variety of needs.

(2) Simple shape, easy installation, increasing the classical beauty.

(3) White fence apart a pool of clear water and green lake which is striking and harmony. Walking in this shore of the lake, we can make a person feel relaxed and happy, forget, and ornamental art and famous celebrities.

\section{Style2: dance with the beautify( as shown in figure 5-2)}

\section{Design concept:}

The overall shape of the pence which reveal the spirit of youth and show youth work hard is lively, vivid and full of vitality. The fence is made in stainless steel. Middle pattern is bright and beautiful, not easy to rust and durable is also suppressed by stainless steel. The variety of patterns is not stick. For example, placed in the vicinity of the stadium, the pattern can be changed into a variety of sports posture, which fully embodies the movement to make people's physical and mental health. Placed in the vicinity of the lake, the water can be changed into lotus and other shapes.

\section{Characteristics:}

(1) more variable form, easy operation

(2) Set and coordinate with the environment

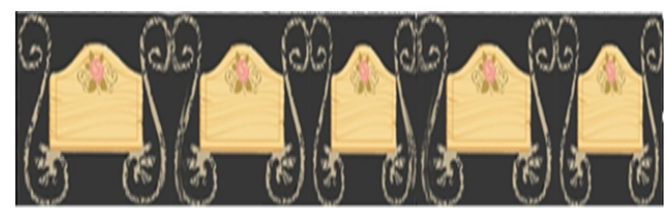

Figure 5-1 Ancient Chinese rhyme

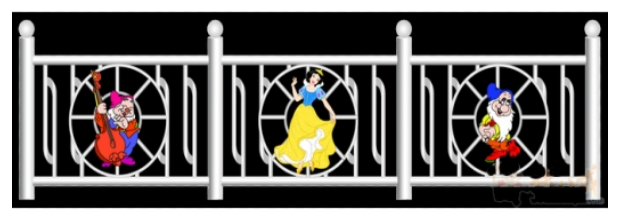

Figure 5-2 dance with the beautify 


\section{Style 3: hand in hand, heart to heart( as shown in figure 5-3)}

\section{Design concept:}

The overall shape of the fence is refined and elegant, highly ornamental which blend the surrounding environment into a whole. The body is a heart, a symbol of a person, and the connection between hearts is the part of the hand. Each person's hand tightly pulled together which mean people work together to create a better tomorrow. The yellow part of the fence is a great achievement for all of us. The fence material is cast iron painted purple which make it sturdy and durable.

\section{Characteristic:}

(1) Simple structure, easy to manufacture

(2) Wearing well, low manufacture cost, excellent publicity.

(3) Not any impact permeability, coordination with environment

\section{Style 4: Moonlight (as shown in figure 5-4)}

\section{Design concept:}

This is a style with Chinese traditional fence that it's frame is cast iron and lotus pond in the middle is all kinds of organic glass decorated with flowers, famous poems etc which comes from the ancient Chinese screen. It can express campus classical scholarly atmosphere.

\section{Characteristic}

(1)Graceful form of fence, use longer, easy to coordinate with the environment.

(2) More complex production
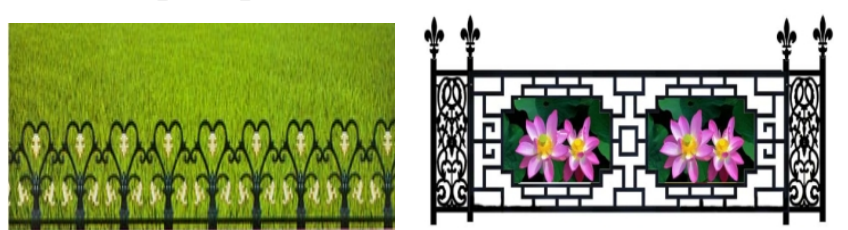

Figure 5-4 Moonlight

Figure 5-3 hand in hand, heart to heart

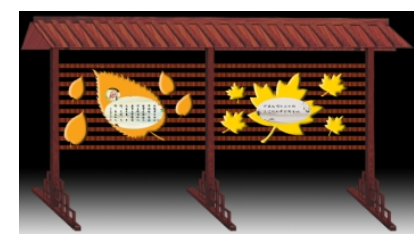

Figure 5-5 Rhyme of forest

high fence

High fence is applied to the main sections of the classroom and dining room, 2.2M High. The shelter is wide with sidewalks.

High fence is applied to classrooms, isolation fence between the cafeteria roads and the surrounding lawn which can both protect the law effectively and take shelter in the rain and snow for students as a cultural promenade, campus landscape. The fence layout is used as the garden of the cultural corridor, and can be designed according to the needs of many columns, such as:

Campus news: electronic subtitles, daily updates

Campus new wave: learn Leifeng, help others, civilize students, "Three good" student, excellent students show.

Learning garden: excellent exercise book; curriculum design; graduation design display.

Life garden: diligent and thrifty, sanitation and the health, fire protection etc Innovation Park: College Students' scientific and technological innovation achievements, Student entrepreneurship competition results show, Teachers' scientific research achievements.

Student employment garden: Guidance of University Student's employment, Employment information etc.

Famous column: Local historical celebrities and famous people who have inspirational role to the students, displaying in different calligraphy font.

Competition program: Student art exhibition, Exhibition of design results.

Style 1: Rhyme of forest ( as shown in figure 5-5) 


\section{Design concept:}

The fence is based on trees. The overall shape of the fence is a column of a tree trunk as a fence. So we use different kinds of trunk to make a fence such as pines, maples, ginkgo trees etc which makes the fence more characteristic of forest. The fence is Used the shape of pine to which is near by combining of the leaves and stems. The shelter is painted the color of the pine leaves on the upper part. We use all kinds of leaves to design the propaganda frame of publicity column. Propaganda frame is mounted on the wood wall stacked by logs. There is a certain gap between the logs.

We put the board of the leaves on the wood block. Each leaf propaganda frame is inlaid the corresponding small leaves as a foil. So the fence is filled with the atmosphere of the forest as a whole. It is more close to nature and coordinates with the surrounding trees and flowers. So that students can feel the connotation of campus culture in this environment.

\section{Characteristics:}

(1)As a hardware facility, it can effectively protect the lawn and beautify the environment;

(2) Used to escape when it snows temporarily

(3) Simple and convenient design and production, obvious effect

(4) Coordinated with the surrounding environment, integral whole.

\section{Style 2:life enjoyment (as shown in figure 5-6)}

\section{Design concept:}

The overall design of the high fence is simple. With stainless steel pipe as the main supporting rod and frame, the top of the fence is designed by using geometric linear design and the front body is the propaganda column which is the cultural corridor column garden used the brick or organic transparent glass. The bottom of the fence is a stone as the base which is conducive to the stability of the whole fence. The plate between the fences can be placed on bonsai to increase beauty and to supply pedestrians for rest.

\section{Characteristics:}

(1) Simple structure, small scale engineer, Wide application scope, significant protective effects.

(2) Simple and easy design, aesthetic feeling, reflected the characteristics of science and Engineering.

(3) Subcontracted each second college, supplied enough space, Strengthen the culture and characteristics of the school.

(4)Accord with campus humanistic design concept, echo with the teaching building and other buildings, harmony.

\section{Style 3: rhythm of life (as shown in figure 5-7)}

\section{Design concept:}

The overall design of the high fence that the main material is plastic and the top of the fence is a wave shaped design is simple which give people a fresh, lively sense of rhythm compared with the previous bar rules. The side of the main body is billboards in four corners of the block used mode of carving art connections. There are plants in two piece of poster board to add to the beauty and improve environmental.

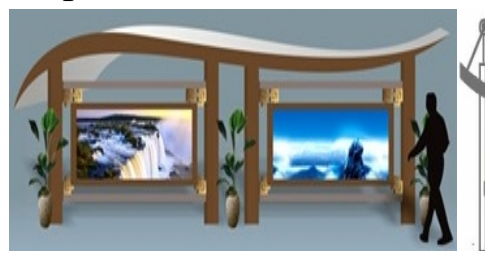

Figure 5-6 life enjoyment

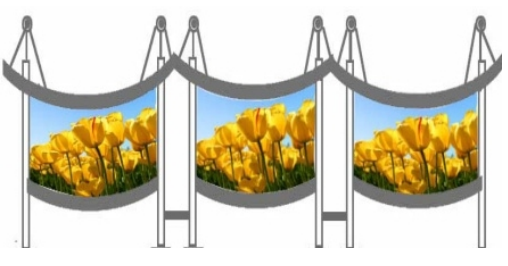

Figure 5-7 rhythm of life

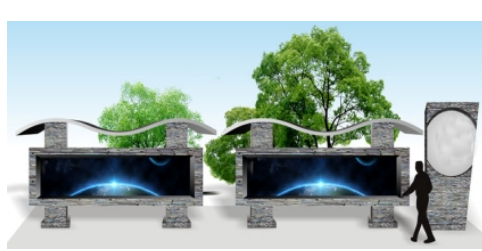

Figure 5-8 rock beautify 


\section{Characteristics:}

(1) Simple structure, small scale engineer, Wide application scope, significant protective effects;

(2) Simple and easy, "beat" aesthetic feeling.

\section{Style 4: Rock beautify (as shown in figure 5-8)}

\section{Design concept:}

The overall design of the high fence that the main material is stone and the top of the fence is a wave shaped design is simple which is more impressive than regular types. It made in stones looks more massive atmosphere. Positive billboards inlaid with glass brick and the reverse side light irradiation which display the latest hot social issues and current affairs information. Publicity bar placed trees and flowers that increase the sense of beauty and improve environmental.

\section{Characteristics:}

(1)Simple and solemn, Simple structure, convenient operation, Wide application scope, significant protective effects;

(2) Design Elegant, Aesthetic feeling, pleasing;

(3)Made in stone, wear well, Bright day and night;

(4) The fence can be placed between plants etc to increase the sense of beauty and to improve the environment.

\section{Management}

After the above targeted campus cultural landscape design, the university campus has been further beautiful. Using these exquisite and distinctive fence designs, skillfully combining with buildings and environment such as flowers, trees, artificial lake and road, the corridor and the vibrant college students harmoniously make every part influence, interact, help and promote mutually. It greatly improves the campus culture atmosphere and active academic atmosphere so that students in the classroom learn knowledge, improve cultivation, cultivate sentiment in a relaxed, harmonious, beautiful environment at the same time, reach the goal that contemporary university teach and educate people harmoniously. However, the excellent design and good facilities need to maintain and manage carefully. Otherwise it will waste money and all the previous efforts. So the school must enhance management to a level and mobilize the students' enthusiasm to participate in the management of the campus fully, to form a harmonious atmosphere "love my school campus, love school as home" .The author's idea is to subcontract all the school's road and fence to various two colleges and universities who implement the contract responsibility system in the principle of proximity and convenience. Column design flexibly and diversely which need the professional characteristics of the college as the main line in addition to the design of those columns (Garden). At the same time, it needs to update the contents of the columns and maintain the column and facilities timely. Students themselves manage, imagine, innovate to design form and column to form a lively, concerting, gratifying situation "love our campus, love the school as home".

Program assessment activities are carried out each semester and every year and find the best one. The end of the year selection results become the annual assessment of the College.

\section{Conclusion}

During the university period, students are experiencing the growth period of the moral experience. The spiritual cultivation is very important to the growth of his life. The campus environment is one of the important aspects of education function. University campus landscape on the role of people's education is not the other landscape can be compared. 
As Churchill said: " People shaped the environment, environment has created a person ". The university is a place to cultivate talents and develop intelligent. It needs a campus environment which can reflect the function of the education. A beautiful campus environment can help to improve people's culture, to enhance self-confidence, to promote interpersonal and information exchange, to cultivate the patriotic spirit.

Any country's university education will highlight the national culture and national spirit. Campus landscape design should reflect a kind of concept, a kind of filled with rich cultural atmosphere. The school has become vitality and positivity in education only after instilling a certain spirit. Therefore the fence author designed is intended to express a spiritual culture and to convey a kind of belief and philosophy. We not only carry forward the national and traditional culture, but also vigorously promote and strive to build a modern culture and civilization, make the dream proposed by Chairman Xi Jinping "building a beautiful country, the Chinese national great new complex new Chinese dream" come true!

\section{References}

[1] Wu Jianguo, "Landscape Ecology-pattern, Process, Scale and Level" [M], Beijing: Higher Education Press.

[2] Lu Yongsen, "Environmental Assessment" [M]. Shanghai: Tongji University Press, 1999, (9).

[3] Zhang Yufen, Road Traffic Environment Engineering [M]. Beijing: People's Communications Press, 2001.4

[4] Jin Lan, Highway Aesthetics,[U.S.] AASHO, Translated by the First Highway Survey and Design Institute [M], Beijing : People's Communications Press, 1981, (1).

[5] Communications Department of Highway Planning and Design Institute: Highway Landscape Design Specification (in Translation) [S]

[6] Ren Futian, Traffic Engineering Psychology [M], Beijing University of Technology, 1989 